\title{
Adhesive Calculation System for Determination of Bonding Glue Needs Using Weighted Product and Lot Sizing Methods
}

\author{
Sistem Kalkulasi Adhesive Untuk Penentuan Kebutuhan Lembonding \\ Menggunakan Metode Weighted Product Dan Lot Sizing
}

Ita Purnamasari

Information System Dept.

ITA.IT@PWI.CO.ID

Faculty of Information Technology

Universitas Serang Raya

Banten, INDONESIA

\section{Agus Setyawan}

GUS.SETYAWAN@HOTMAIL.COM

Information System Dept.

Faculty of Information Technology

Universitas Serang Raya

Banten, INDONESIA

\author{
Ryan Naufal Hay's \\ Information System Dept. \\ Faculty of Information Technology \\ Universitas Serang Raya \\ Banten, INDONESIA
}

Corresponding Autor: Ryan Naufal Hay’s

\begin{abstract}
The production process that exists at PT. Parkland World Indonesia consists of several parts of the production process, one of which is the production process ofondonding which is used for shoe glue between outsole and upper. Adhesive is a material that is able to connect or unite the two surfaces of separate objects so that it has adequate strength when subjected to the load. This study discusses the making of an adhesive calculation system as a determination of the need for the first time to be ordered, using the weighted product method and lot sizing. The application was developed using the Power Builder programming language with Sybase SQL anyware as its database. With this system will help managers or superiors to know and determine alternative priorities or types of adhesive needs that must be prioritized for adhesive needs to help smooth the production process. To minimize the total cost of adhesive requirements.
\end{abstract}

Keywords: Weighted product, Lot sizing, Kalkulasi adhesive, Power Builder

\begin{abstract}
ABSTRAKSI
Proses produksi yang ada pada PT.Parkland World Indoneisa terdiri beberapa bagian proses produksi, salah satunya adalah proses produksi lembonding yang digunakan untuk perekat sepatu antara outsole dan Upper. Adhesive adala bahan yang mampu menyambungkan atau menyatukan kedua permukaan benda yang terpisah
\end{abstract}

C2019 Purnamasari, Setyawan, Hay's

This is an open access article under the CC-BY-NC-SA license. 
sehingga mempunyai kekuatan yang memadai saat dikenai beban tersebut. Penelitian ini membahas tentang pembuatan sistem kalkulasi adhesive sebagai penentuan kebutuhan lembonding yang pertama kali akan diorder, dengan menggunakan metode weighted product dan lot sizing. Aplikasi dikembangkan dengan bahasa pempograman Power Builder dengan Sybase SQL anyware sebagai basis datanya. Dengan adanya sistem ini akan membantu manager atau atasan untuk mengetahui dan menentukan prioritas alternatif atau jenis kebutuhan adhesive yang harus diprioritaskan untuk kebutuhan adhesive guna membantu kelancaran proses produksi. Untuk meminimalkan total biaya kebutuhan adhesive.

Keywords: Weighted product, Lot sizing, Kalkulasi adhesive, Power Builder

\section{Pendahuluan}

Proses produksi yang ada pada PT. XYZ terdiri beberapa bagian proses produksi, salah satunya adalah proses produksi lem bonding yang digunakan untuk perekat(adhesive) sepatu antara outsole dan Upper. Untuk dapat memenuhi kebutuhan proses produksi lembonding maka persediaan bahan baku adhesive harus dikelola dengan baik, agar proses produksi terus berjalan sesuai dengan permintaan pelanggan atau memenuhi kebutuhan pasar. Persediaan bahan baku adhesive tidak boleh kurang atau lebih. Jika persediaan bahan baku adhesive kurang, akibatnya akan menghambat proses produksi bahkan sampai terhenti. Jika persediaan bahan baku adhesive berlebihan maka akan mengganggu proses penyimpanan dan menimbulkan biaya berlebihan. Kedua kondisi tersebut berpengaruh terhadap besarnya biaya produksi. Dengan adanya pengaturan perencanaan persediaan bahan baku adhesive yang baik, diharapakan akan memberikan peningkatan efesiensi untuk meningkatkan biaya produksi.

Analisa persediaan bahan baku adhesive merupakan salah satu aspek bagi berlangsungnya kelancaran suatu produksi. Hal ini berlaku untuk semua industri yang bergerak dalam bidang manufacturing, seperti industri sepatu. Analisa bahan baku adhesive pada produk sepatu merupakan salah satu sistem yang dapat menjamin kelancaraan akan ketersediaan bahan baku adhesive sehingga proses produksi akan berjalan dengan lancar. Analisa tersebut mencegah terjadinya kekurangan bahan baku yang dapat mengakibatakan keterlamabatanya proses produksi atau penghentian kegiatan produksi yang menyebabkan perusahaan menderita kerugian.

Adhesive ini juga sangat berpengaruh dalam kelancaran produksi di PT. XYZ untuk lem bonding sepatu, jika tidak ada kalkulasi atau perhitungan semua bahan adhesive tidak bisa di ambil untuk jatah material dalam pembuatan adhesive. Terdapat metode-metode yang berbeda untuk menangani setiap bentuk persediaan, salah satunya adalah metode yang bisa digunakan untuk mengendalikan tingkat persediaan bahan baku yang sifatnya tergantung pada jumlah produk akhir yang diproduksi yaitu system material requirmenet planning (MRP). Salah satu faktor yang perlu dipertimbangkan dalam implementasi MRP adalah penggunaan teknik lot sizing yang tepat sehingga dapat meminimalkan biaya total persediaan. Lot sizing merupakan penentuan ukuran lot pengadaan untuk material yang dimaksud. Terdapat beberapa macam teknik lot sizing yang tujuannya untuk meminimalkan biaya total persediaan yang terjadi dari biaya penyimpanan dan biaya pemesanan, dan memperlancar proses produksi.

\section{Tinjauan Pustaka}

Metode weigted product telah banyak digunakan sebagai alat bantu pendukung keputusan untuk berbagai keperluan. Beberapa diantaranya digunakan untuk SPK pemberian bonus pegawai pada hotel alamanda (Permatasari, 2012), untuk model masalah Multiple Atrribute Decision Making (MADM) (Deviyanti, 2012), merupakan salah satu metode penyelesaian multi kriteria dimana dalam perkekrutan karyawan banyak kriteria yang harus diperimbangkan (Diah, 2011), dapat membantu manager dalam menentukan karyawan yang berhak di rekomendasikan mendapat bonus proses pembobotan multikriteria dan seleksi dengan lebih cepat, cermat dan lebih efektif (Jaya, 2010), untuk menghasilkan nilai pada setiap alternatif(S), penentuan nilai setiap alternatif $(\mathrm{V})$ dengan membagi nilai alternatif (S) dengan jumlah total alternatif (S), Alternatif (V) dengan nilai tertinggi menjadi alternatif terbaik (Andrianto dan Santoso, 2013), diharapkan proses penjurusan siswa lebih efektif ada efesien sehingga siswa cepat mendapatkan infomasi tentang penjurusan dan hasil penjurusan pun sesuai dengan kemampuan masing-masing siswa, sehingga jika terjadi kesalahan dalam penginputan nilai atau data siswa, maka data yang salah tersebut dapat diperbaiki tanpa harus menginput ulang nilai atau data siswa (Sianturi, 2013), menunjukkan pemanfaatan Weighted Product sebagai model sistem pendukung keputusan penentuan siswa kelas unggulan pada SMP Negeri 3 Tanjung Morawa, dapat membantu admin dalam menentukan siswa yang berhak masuk kekelas 
unggulan, dengan pembobotan multi kriteria dan sleksi dengan lebih cepat, cermat dan lebih efektif (Koko, 2010), SPK ini merupakan sistem yang dapat membantu kepala daerah dalam menentukan SSN/SKM pada setiap sekolah, dan menggunakan aplikasi web untuk mengelola data dalam proses sistem penunjang keputusan. Dengan adanya perangakat ini diharapkan akan memudahkan kepala daerah dalam menentukan keputusan (Jusuf dkk, 2010), karena instansi cukup memilih beberapa barang yang akan menjadi alternatif pemilihan dan memberikan nilai bobot pada perbandingan alternatif dan kriterianya, adapun kriteria tersebut adalah omset, tenaga kerja, target pasar, teknologi, spesifikasi, asal bahan baku, jumlah bahan baku (Alfita, 2010), Penerapan dari metode ini dapat menentukan desa dengan prioritas teringgi untuk mendapatkan BLM dari sekian alternatif desa pengusul (Ahmadi dan Wiyanti, 2014), menjadi saran yang dapat dipertimbangkan oleh konsumen serta menjadi sarana informasi untuk mendapatkan informasi mengenai TV (Ningrum, 2012), penelitian membuat sebuah sistem yang diharapkan nantinya dapat membantu pengambilan keputusan dalam pemilihan sepeda motor tersebut. Maka dari itu perlu dibuat suatu sistem pendukung keputusan untuk mengatasi masalah pemilihan sepeda motor tersebut (Rani, 2010), Peningkatan Prestasi Akademik (PPA) dengan metode weighted Product" Tujuan penelitian ini adalah menjelaskan proses perankingan calon peneriam beasiswa PPA tahun 2011 di FMIPA UNS dengan menggunakan metode WP. Perankingan dengan metode WP dipengaruhi oleh banyaknya kriteria, perbandingan tingkat kepentingan antar kriteria, dan pangkat bobot kriteria pada kriteria. Hasil perankingannya berdasarkan pada preferensi relatif yang terbesar sampai yang terkecil (Ningrum dan Putri, 2012), pengujian validasi (pengujian black box) dan pengujian akurasi sistem pakar. Hasil pengujian validasi yaitu $100 \%$ yang menunjukkan bahwa fungsionalitas sistem dapat berjalan dengan baik sesuai dengan daftar kebutuhan. Hasil pengujian akurasi yaitu 86,6\% yang menunjukkan bahwa sistem pendukung keputusan dapat berfungsi dengan baik sesuai dengan metode Weighted Product (Alfinda dkk, 2014), Sistem ini dirancangn sebagai alat bantu tenaga medis dalam mendiagnosis pasien pneumonia dan menurunkan tingkat keterlambatan penanganan terhadap pasien pneumonia dan meminimalisir adanya kesalahan pemberian antibiotik terhadap pasien pneumonia. Sistem diuji dengan cara memasukan gejalagejala pneumonia tanpa melibatkan seorang paxar, dan menunjukan bahwa sistem dapat mendukung untuk mendiagnosis penyakit pneumonia (Syaukani dkk, 2012), membangun sebuah sistem pendukung keputusan untuk penentuan penelitian ini, dalam suatu perusahaan serta yang dibuat dapat membantu mengambil keputusan bagi PT.Parkland World Indonesia untuk penentuan lokasi gudang (Sari dkk, 2011).

\section{Weigted Product dan Lot Sizing}

Metode Weighted Product merupakan salah satu metode penyelesaian yang ditawarkan untuk menyelesaikan masalah Multi Attribute Decision Making (MADM). Metode Weighted Proudct (WP) mirip dengan metode Weighted Sum (WS), hanya saja metode Weigted Product (WP) terdapat perkalian dalam perhitungan matematikanya. Metode Weighted Product (WP) juga disebut analisis berdimensi karena struktur matematikanya menghilangakan satuan ukuran. Metode Weighted Product (WP) adalah himpunan berhingga dari alternatif keputusan yang dijelaskan dalam beberapa hal kriteria keputusan [17].

a. Input data yang akan dihitung menggunkan weighted product, masukan data alternative, definisikan terlebih dahulu jenis kriterianya, apakah termasuk criteria keuntungan apa criteria biaya.

b. Sebelumnya akan dilakukan perbaikan bobot terlebih dahulu, akan diperbaiki sehingga total bobot dihitung dengan persamaan sebagai berikut :

$W_{j}=\frac{W_{j}}{\sum_{j=1}^{n} W_{j}}$

c. Preferensi Ai diberikan pada rumus sebagai berikut :

$$
S_{i=} \prod_{j=1}^{n} X_{i j} W^{j}
$$

Dengan $1=1,2 \ldots$, m Dimana $\sum w j=w j$ adalah pangkat bernilai positif untuk attribute keuntungan, dan bernilai negatif untuk attribute biaya.

d. Preferensi relatife dari setiap alternatife, diberikan pada rumus sebagai berikut :

$$
V_{(A i)}=\prod_{j=1}^{n} X_{i j} W^{j} z
$$


Lot sizing merupakan teknik dalam meminimalkan jumlah barang yang akan dipesan, sehingga dapat meminimalkan total biaya persediaan [19]. Metode Economic Order Quantity (EOQ) adalah salah satu metode dalam manajemen persediaan yang klasik dan sederhana, perumusan metode EOQ pertama kali ditemukan oleh FW Harris pada tahun 1915, tetapi metode ini sering disebut EOQ Wilson karena metode ini dikembangkan oleh seorang peneliti bernama Wilson pada tahun 1934. Metode ini digunakan untuk menghitung minimalis total biaya persediaan berdasarkan persamaan tingkat atau titik equlibrium kurva biaya simpan dan biaya pesan. Metode EOQ mengasumsikan permintaan secara pasti dengan pemesanan yang dibuat secara konstan serta tidak adanya kekurangan persediaan[18].

1) Perumusan metode EOQ didapat dari penurunan biaya total. Karena tujuan utama dari penggunaan metode EOQ adalah untuk meminimumkan biaya persediaan yang mencakup biaya pembelian, biaya simpan bahan baku dan biaya pengadaan. Untuk biaya total dapat dinyatakan sebagai berikut:

$$
\mathrm{BT}(\mathrm{Q})=\mathrm{TB}+\mathrm{TS}+\mathrm{TP}
$$

2) Dengan $\mathrm{TB}=\mathrm{BD}, \mathrm{TS}=\zeta_{2}^{Q}, \mathrm{TP}=P_{Q}^{D}$ dapat di transformasiakan ke dalam bentuk lain menjadi:

\section{Metodologi Penelitian}

$$
\mathrm{EOQ}=\mathrm{B} \cdot \mathrm{D}+\zeta_{2}^{Q}+P_{Q}^{D}
$$

Penelitian ini diawali dengam mengumpulkan data alternative group item adhesive. Criteria yang terlibat sebanyak tiga, yang digunkan dalam penelitian ini adalah total order adhesive, stock adhesive dan request adhesive. Data alternative dari masing-masing group item adhesive di kelola menggunkana weighted product yang nantinya akan digunakan sebagai alternative terbaik, yang akan di pilih sebagai orderan adhesive yang pertama kali di order ke purchasing. Setelah mendapatkan alternative terbaik dihitung menggunakan lot sizing, agar bisa mengetahui biaya kebutuhan adhesive setiap bulannya. Untuk meminimalkan jumlah barnag yang akan dipesan, sehingga dapat meminimalkan total biaya persediaan.

\section{$5 \quad$ Hasil dan Pembahasan}

Penelitian ini menguji sebanyak 13 group item adhesive, sesuai dengan criteria yang telah ditentukan. Data pengujian terdiri atas 3 kriteria yaitu total request adhesive(C1), stock adhesive(C2) dan request adhesive(C3). Penentuan kategori berdasarkan kriteria sebagai berikut :

1) Kategori setiap criteria Kriteria $\mathrm{C} 1$ (Total Order Adhesive) dan $\mathrm{C} 3$ (Requestadhesive) adalah kriteria biaya

2) Kriteria C2 (Stock Adhesive) adalah kriteria keuntungan.

Tabel 1. Nilai kriteria untuk setiap alternative

\begin{tabular}{cccc}
\hline \multirow{2}{*}{ Alternatif } & \multicolumn{3}{c}{ Kriteria } \\
\cline { 2 - 4 } & C1 & C2 & C3 \\
\hline \hline A1 & 16523.81 & 1877 & 14646.81 \\
\hline A2 & 3482.51 & 288 & 3194.51 \\
\hline A3 & 28220.45 & 1508.74 & 26711.71 \\
\hline A4 & 8211.27 & 1192.54 & 7018.73 \\
\hline A5 & 27779.9 & 1321 & 26458.9 \\
\hline A6 & 2313.97 & 50 & 2263.97 \\
\hline A7 & 17328.71 & 3198 & 14130.71 \\
\hline A8 & 4438.55 & 1370 & 3068.55 \\
\hline A9 & 54262.96 & 2526.2 & 51736.76 \\
\hline A10 & 4669.76 & 457 & 4212.76 \\
\hline A11 & 1614.49 & 400 & 1214.49 \\
\hline A12 & 444.08 & 25 & 419.08 \\
\hline A13 & 464.57 & 125 & 339.57 \\
\hline \hline
\end{tabular}

Sumber: PT.Parkland World Indonesia setelah diolah 
Perbaikan bobot terlebih dahulu sehingga total bobot $\sum \mathrm{w}=1$ dengan cara $W^{j}=W^{j}$

$$
\begin{aligned}
& W^{1}=\frac{4 b}{4 b+38+22}=0.40 \\
& W^{2}=\frac{38}{4 b+38+22}=0.38 \\
& W^{3}=\frac{22}{4 b+38+22}=0.22
\end{aligned}
$$

Kemudian vektor S dapat dihitung sebagai berikut :

$$
\begin{aligned}
& \zeta^{1}=\left(16523.81^{-0.4 \mathrm{D}}\right)\left(1877^{\mathrm{D.3S}}\right)\left(14646.81^{-\mathrm{D} .22}\right)=0.04365 \\
& 5^{2}=\left(3482.51^{-\mathrm{D} A \mathrm{D}}\right)\left(288^{\mathrm{D} .38}\right)\left(3194.51^{-\mathrm{D} .22}\right)=0.05581 \\
& 5^{3}=\left(28220.45^{-0.45}\right)\left(1508.74^{0.38}\right)\left(26711.71^{-0.22}\right)=0.02841 \\
& S^{4}=\left(8211.27^{-0.4 \mathrm{D}}\right)\left(1192.54^{\mathrm{D} .38}\right)\left(7018.73^{-0.22}\right)=0.05714 \\
& S^{5}=\left(27779.9^{-0.45}\right)\left(1321^{0.38}\right)\left(26458.9^{-0.22}\right)=0.02725 \\
& S^{6}=\left(2313.97^{-D .45}\right)\left(50^{\mathrm{D} .38}\right)\left(2263.97^{-0.22}\right)=0.03644 \\
& S^{7}=\left(17328.71^{-\mathrm{D} .4 \mathrm{~V}}\right)\left(3198^{\mathrm{D} .38}\right)\left(14130.71^{-0.22}\right)=0.05287 \\
& S^{8}=\left(4438.55^{-0.40}\right)\left(1370^{0.38}\right)\left(3068.55^{-0.22}\right)=0.09244 \\
& S^{9}=\left(54262.96^{-0.4 \mathrm{D}}\right)\left(2526.2^{0.38}\right)\left(51736.76^{-0.22}\right)=0.02301 \\
& 5^{1 \mathrm{D}}=\left(4669.76^{-\mathrm{D} .4 \mathrm{~b}}\right)\left(457^{\mathrm{D} .38}\right)\left(4212.76^{-\mathrm{D} .22}\right)=0.05566 \\
& S^{11}=\left(1614.49^{-\mathrm{D} .4 \mathrm{D}}\right)\left(400^{\mathrm{D} .38}\right)\left(1214.49^{-0.22}\right)=0.10640 \\
& 5^{12}=\left(444.08^{-0.40}\right)\left(25^{0.32}\right)\left(419.08^{-0.22}\right)=0.07858 \\
& 5^{13}=\left(464.57^{-\mathrm{D} A \mathrm{D}}\right)\left(125^{\mathrm{D} .32}\right)\left(339.57^{-\mathrm{D} .22}\right)=0.14898
\end{aligned}
$$

Nilai vektor V yang akan digunakan untuk perankingan diperoleh sebagai berikut:

$$
\begin{aligned}
& \mathrm{V} 1=0.05411 \\
& V 2=0.06918 \\
& V 2=0.03522 \\
& V 2=0.07083 \\
& V 2=0.03378 \\
& V 2=0.04517 \\
& V 2=0.06554 \\
& V 2=0.11459 \\
& V 2=0.02852 \\
& V 2=0.06900 \\
& V 2=0.13190 \\
& V 2=0.09741 \\
& V 2=0.18469
\end{aligned}
$$

Nilai V13 menunjukan nilai terbesar sehingga alternatif A13 adalah alternatif yang terpilih sebagai alternatif terbaik. Dengan kata lain Negative Press yang akan di pilih sebagai orderan adhesive yang pertama kali di order ke purchasing. Dan untuk menghitung kebutuhan adhesive menggunakan teknik lot sizing, akan diberiakan lima alternatif yang mempunyai nilai tertinggi untuk dihitung menggunakan metode lot sizing.. Pencarian dengan lot sizing, Ada lima alternatif dari Weighted Product yang menjadi sample untuk menghitung menggunakan metode lot sizing yaitu, NEGATIVE PRESS, ANTITACK, DEGREASER, PAINTING, dan SEWING, salah satu contoh menggunkaan perhitungan lot sizing adalah negative press. 
Tabel 2. Group Item Negarive Press

\begin{tabular}{|c|c|c|c|c|c|c|}
\hline $\begin{array}{l}\text { Group } \\
\text { Item }\end{array}$ & Item & Harga/Unit & $\begin{array}{c}\text { Permintaan } \\
\text { Perencanaan }\end{array}$ & $\begin{array}{l}\text { Harga } \\
\text { Stock }\end{array}$ & Frekuensi & $\begin{array}{c}\text { Biaya } \\
\text { Pesanan }\end{array}$ \\
\hline \multirow{4}{*}{$\begin{array}{l}\text { NEGATIVE } \\
\text { PRESS }\end{array}$} & MOCA SH & $\$ 4.70$ & 88.50 & $\$ 191.10$ & 1.85 & $\$ 1,109.80$ \\
\hline & DSE $295 \mathrm{P}$ & $\$ 6.40$ & 129.64 & $\$ 460.80$ & 1.44 & $\$ 368.92$ \\
\hline & $\begin{array}{llll}\text { CLPU } & 80 & \text { C-A } & \text { /CLPU } \\
\text { CA-Y } & & & \end{array}$ & $\$ 7.00$ & 129.77 & $\$ 140.00$ & 1.85 & $\$ 768.36$ \\
\hline & $\begin{array}{l}\text { CLPU } 80 \text { C-B/CLPU 80- } \\
\text { B }\end{array}$ & $\begin{array}{l}\$ \\
7.00\end{array}$ & 116.66 & $\$ 140.00$ & 1.83 & $\$ 676.65$ \\
\hline
\end{tabular}

\section{Kesimpulan}

Penelitian ini berhasil melakukan pengujian dari beberapa proses utama yang menggunakan perhitungan dan analisis dengan melibatkan perhitungan secara manual, dapat diketahui bahwa hasil yang didapatkan dari perhitungan manual sama dengan perhitungan oleh sistem. Sehingga secara umum sistem telah bekerja dengan baik karena proses perhitungan telah sesuai dengan yang diharapkan. Sistem ini mampu mengolah data alternatif terbaik dari sejumlah alternatif yang ada, karena proses perengkingan setelah menentukan nilai bobot untuk setiap kriteria. Setelah menentukan nilai bobot dan mengisi jumlah kriteria pada setiap alternatif, maka sistem dapat mengolah proses perhitungan vector sehingga menghasilkan nilai alternatif terbaik dari sejumlah alterntif yang ada. Sistem ini mengolah proses perhitungan vector sehingga menghasilkan nilai alternatif yang ada. Sistem ini dapat menjadi sarana penyimpanan data-data tersebut sehingga dapat didokumentasikan.

\section{References}

Permatasari, Yuke 2012 "Sistem Pendukung Keputusan Pemberian Bonus Pegawai Pada Hotel Alamanda Klaten Dengan Menggunakan Metode Weighted Product" Sekolah tinggi manajemen informatika dan computer AMIKOM Yogyakarta

Deviyanti, Geotiffany 2012 "Pembangunan Sistem Pendukung Keputusan Pemilihan Hotel Di Yogyakarta Dengan Metode Weighted Product Berbasis WEB" Program studi teknik informatika fakultas teknologi industry Universitas ATMA Jaya Yogyakarta

Diah, Ardi Kusumaning R, 2011 "Sistem Pendukung Keputusan Rekruitment Karyawan Produksi Menggunakan Metode Weighted Product Pada PT. Ploss Asia Semarang” Program Studi Sistem Informasi, Fakultas Ilmu Komputer Universitas Dian Nuswantoro, Semarang.

Jaya, Putra, 2010 "Sistem Pendukung Keputusan Penentuan Bonus Karyawan menggunakan Metode Weighted Product (WP) (Studi Kasus: PT.Gunung Sari medan)" Volume V No 2 hal:90 s.d 95

Andrianto, Djoko, Santoso, Heru, 2013 "Sistem Pendukung Keputusan Pemilihan Jurusan Dengan Metode Weighted product Untuk Siswa-Siswi SMA Negeri 1 Sale” Published Version.download

Sianturi, Ingot Seen, 2013 "Sistem Pendukung Keputusan Untuk Menentukan Pemilihan Jurusan Siswa Dengan Menggunakan Metode Weighted Product (Studi Kasus: SMA Swasta HKBP DolokSanggul" Majalah ilmiah, Informasi dan Teknologi Ilmiah (INTI) ISSN: 2339-210X

Koko, Adi, 2010 "Sistem Pendukung Keputusan Untuk Menentukan Siswi Kelas Unggulan Pada SMP Negeri 3 Tanjung Morawa dengan Menggunakan Metode Weighted Product" Volume VI No 1 Hal 87 s.d 92

Jusuf, Abdurrahman K, Lahinta, Agus, Novian,Dian, tanpa tahun"Penerapan Metode Weighted Product (WP) Dalam Penentuan Sekolah Standar Masional (NNS)/Sekolah Kategori Mandiri (SKM) SMA/SMK/MA", Universitas Negeri Gorontalo, hal: 1-10

Alfita,Riza Rani, 2010 "Perancangn Sistem Pendukung Keputusan Penentuan Prioritas produk Unggulan Daerah Menggunkan Weighted Product” sistem pendukung keputusan

Ahmadi, Aziz, Wiyanti Dian Tri 2014 "Implementasi Weighted Product (WP) Dalam Penentuan Penerimaan Bantuan Langsung Masyarakat PNPM Mandiri Perdesaan” Seminar Nasional Aplikasi Teknologi Informasi (SNATI) Yogyakarta, ISSN: 1907:5022

Ningrum, Wahyu Retno, 2012 "Sistem Pendukung Keputusan Untuk Merekomendasikan TV Layar Datar Menggunakan Metode Weighted Product (WP)" Program studi teknik informatika fakultas teknologi informasi universitas Kristen satya wacana salatiga.

Rani, Sasika 2010 "Sistem Pendukung Keputusan Pemilihan Sepeda Motor Berbasis Web Dengan Metode Weighted Product” Jurnal Sistem Pendukung Keputusan Volume : Volume VII No 3 Hal : 62 s.d 66 
Ningrum, Debora Dwi Putri, 2012 "Sistem Pendukung Keputusan Untuk Merangking Calon Penerima Beasiswa Peningkatan Prestasi Akademik (PPA) Dengan Metode Weighted Product" Surakarta-F.MIPA-2012, UNSF.MIPA Jur.Matematika-M0104024-2012.

Alfinda, Litha Astriana, Soebroto, Arief Andy, Putri, Rekyan Regasari Mardi, 2014 "Sistem pendukung Keputusan Pemilihan Penerima Jamkesmas Metode Weighted Product" (C2014 by Doro jurnal Volume 3-Number 6

Syaukani, Muhamad, Kusnanto, Hari, 2012 "Pemodelan Sistem Pendukung Keputusan Kelompok Dengan Metode Fuzzy Weighted Product Untuk Diagnosis Penyakit Pneumonia”, Jurnal Teknologi, Volume 5 Nomor 1, Juni 2012, Hal: 17-23

Sari, Indah Kumala, Lulu W, Yohana Dewi, Diah K, Kartina., 2011, "Sistem Pendukung Keputusan Penentuan lokasi Gudang di Perusahaan dengan Metode Weighted Product “, Politeknik Caltex Riau-Jl Umbasari nol Pekanbaru, Hal $1-6$

Techno, Neatia, 2014 “Metode Weighted Product (WP) Dalam Sistem Pendukung Keputusan SPK)” NERIMS

Setiawan,Ari, 2014 "Analisa Perbandingan Metode Perusahaan, Economic Order Quantity dan Period Order Quantity Dalam Mengopatimalisasi Pengendalian Persediaan Bahan Baku" Universitas Pendidikan Indonesia, Repository.upi.edu, perpustakaan.upi.edu. 